\title{
Establishing Social, Cognitive and Teacher Presences During Emergency Remote Teaching: Reflections of Certified Online Instructors in the United Arab Emirates
}

\author{
Lawrence Meda \\ Zayed University, Dubai, United Arab Emirates \\ ORCID: 0000-0002-9496-9132 \\ Areej EISayary \\ Zayed University, Dubai, United Arab Emirates \\ ORCID: 0000-0002-5554-0069
}

Received: 11 Mar 2021

Accepted: 19 May 2021

\begin{abstract}
COVID-19 has forced many universities across the globe to implement emergency remote teaching as a preventative measure. Many faculty staff members were not adequately equipped with knowledge and skills of facilitating remote teaching. This made the establishment of social, cognitive and teacher presences difficult for them. The purpose of this study is to examine ways in which certified online instructors established social, cognitive and teacher presences during emergency remote teaching at a university in the United Arab Emirates. The study is guided by one critical question: How did certified online instructors establish social, cognitive and teacher presences in their online classes during the COVID-19 pandemic? The study adopted a qualitative case study within an interpretivist paradigm. Two certified online instructors were purposely selected to reflect on their experiences in establishing social, cognitive and teaching presences in their remote classes. It was found that students' engagement, critical thinking and self-directed learning and continual engagement play an indispensable role in students' remote learning. The study concludes that the establishment of the three components of a community of inquiry enhance students' learning experiences and allow instructors to cater for the diverse learning needs of all students in an online community.
\end{abstract}

Keywords: emergency remote teaching, social presence, teaching presence, cognitive presence, online learning

\section{INTRODUCTION}

The global pandemic of COVID-19 forced many institutions of higher learning across the globe to resort to emergency remote teaching (ERT) with a limited amount of time to prepare for virtual classes. Many institutions which predominantly used face-to-face classes experienced a rough transition as they did not have ample time to prepare for virtual classes (Ontong \& Waghid, 2020) and others did not have adequate resources (Ngwacho, 2020). Rapanta, Botturi, Goodyear, Guàrdia and Koole (2020, p. 923) said, "a particular challenge has been the urgent and unexpected request for previously face-to-face university courses to be taught online." Karkar, Fatlawi, and Al-Jobouri (2020), and Kibuku, Ochieng, and Wausi (2020) posit that in some developing countries, some students had difficulties accessing remote learning as they faced barriers accessing technologies and internet connection. Some institutions where online learning and blended 
learning modalities were already implemented were even affected by the global pandemic as it caused panic among students and faculty staff (Bozkurt et al., 2020).

Before delving much into the issues at play, it is essential to clarify the two terms online learning and ERT. Bozkurt and Sharma (2020) submit that although the terms are sometimes used interchangeably, they are not synonymous. Online learning differs significantly from ERT in the sense that it is (online learning) well planned in terms of course designing and the selection and organisation of students' learning experiences (Draves, 2013). This is different from ERT which Affouneh, Salha, and Khlaif $(2020$, p. 1) conceptualised as:

\begin{abstract}
Not usually planned in advance and involves a sudden shift from traditional teaching into a remote one in view of emergency situations like the outbreak of Coronavirus in different countries. This is a totally different situation compared to e-Learning in normal circumstances. After an emergency state, everything is supposed to go back to normalcy. Moreover, educators have to work in a highly stressful situation while having no knowledge of the end of the crisis.
\end{abstract}

The current learning strategy being implemented by many universities that used to offer predominantly faceto-face classes is not online learning but ERT, as it is responsive to the COVID-19 pandemic (Zhang et al., 2020). The university where this study was conducted was implementing ERT as it is hoped that when the pandemic is over, the institution will revert to its conventional face-to-face classes. Faculty staff members were not fully prepared for remote learning which made it difficult for some to establish social and cognitive presences to enhance students' learning experiences.

There exists surfeit literature that focuses on students' and lecturers' experiences of ERT and how they establish the Community of Inquiry (Col) framework in their classes. However, there is a dearth of scholarship on reflections of certified online instructors on how they establish the social, cognitive and teaching presences. A lack of knowledge in this area is what this study seeks to address.

\title{
Purpose of the Study
}

The purpose of this study is to examine ways in which certified online instructors established social, cognitive and teacher presences during ERT at a university in the United Arab Emirates (UAE). The study is guided by one critical question: How did certified online instructors establish social, cognitive and teacher presences during ERT?

The paper begins by presenting literature on the Col framework and how it has been established in some studies. This is followed by context of the study and a short description of the online instruction course which was completed by certified online instructors. Research design and methods are presented thereafter, followed by findings and discussion. The paper ends with a succinct conclusion and implications.

\section{The Community of Inquiry Framework}

A theoretical framework guiding this study is the Col framework which consists of three interconnected components: social presence, teaching presence and cognitive presence. There is a need for analysing the three components of Col jointly as they influence each other in ERT (Gutiérrez-Santiuste, Rodríguez-Sabiote, \& Gallego-Arrufat, 2015). The three components are illustrated on Figure 1 and are discussed in depth. 


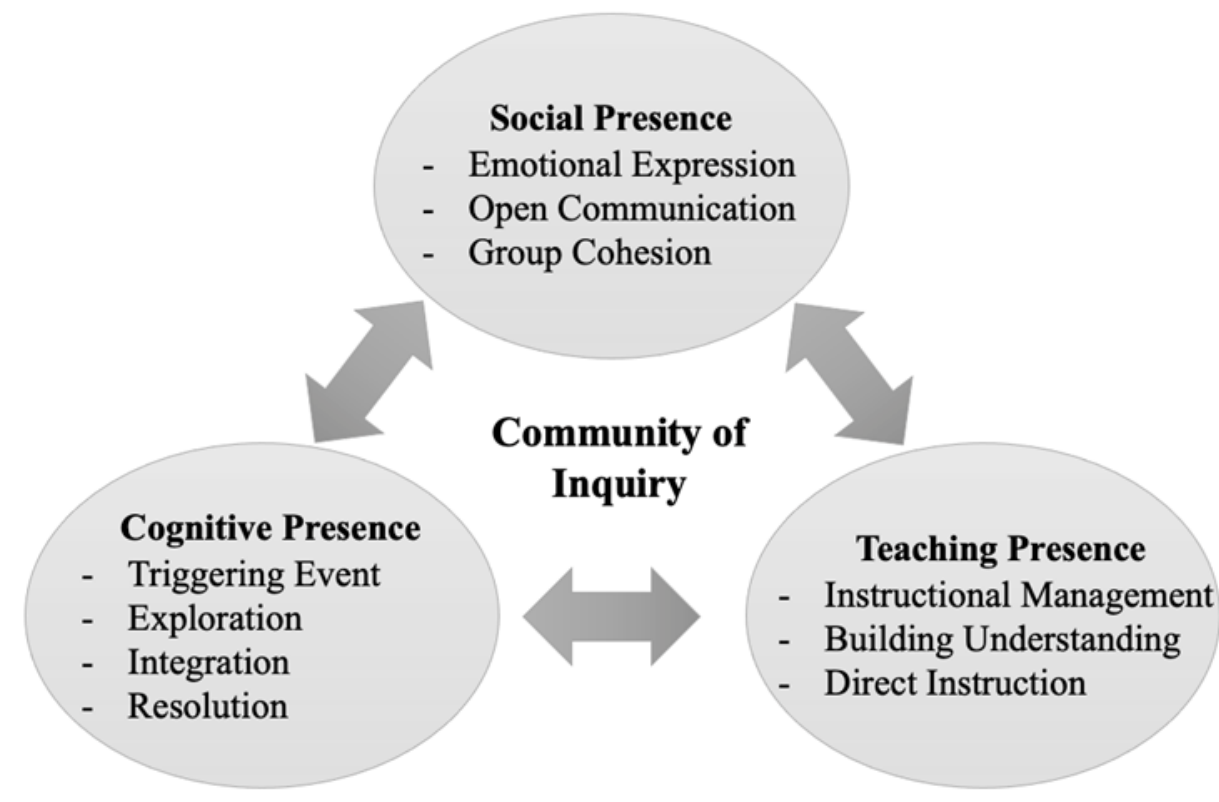

Figure 1. Community of Inquiry Framework adapted from Garrison et al. (2000)

\section{Social presence}

Garrison et al. (2000, p. 94) define social presence as "the ability of participants in a community of inquiry to project themselves socially and emotionally, as 'real' people (i.e., their full personality) through the medium of communication being used." It is the degree to which students interact and connect with each other in an online community (Garrison, 2015). It involves online communication among students and with their instructor. It allows students to express their feelings openly and work collaboratively to achieve a common educational goal. Draves (2013) states social presence is essential as it establishes the human aspect of an online community and allows students to engage meaningfully in order to achieve educational goals. Social presence consists of three key categories:

- First, open communication, which involves reciprocal and respectful exchange of information where a student will recognise and acknowledge other students' contributions, critique the views and be respectful (Garrison et al., 2000). If a conducive online learning environment where open communication prevails is created, students will feel free to express themselves.

- The second category of social presence is emotional expression. Emotions such as togetherness, warmth and attraction, which are experienced in face-to-face classes, are often limited in virtual classes. This brings about the expression of emotion category where students in an online community show emotions and reflect socio-emotional components of communication in order to form interpersonal relationships (Kreijns et al., 2014). Garrison et al. (2000, p. 99) submit that "emotional expression is indicated by the ability and confidence to express feelings related to the educational experience."

- The third category of social presence is group cohesion which encourages collaboration among students. It involves students' activities which build and sustain a sense of group commitment (Garrison, Anderson, \& Archer, 2001). Collaboration is enhanced when students engage in a critical, challenging, responsive and respectful manner (Garrison et al., 2000).

\section{Cognitive presence}

According to Garrison (2007, p. 65), "Cognitive presence is defined as the exploration, construction, resolution and confirmation of understanding through collaboration and reflection in a community of inquiry." This means cognitive presence requires students to be able to construct meaning through discourse and sustained reflection (Garrison et al., 2001). Anderson (2004) concurs that cognitive presence involves 
students' use of critical thinking skills in order to construct new knowledge, meaning and understanding through a deep and sustained reflection (Anderson \& Dron, 2011).

Students will be interacting with one another, constructing meaning through arguments and critically reviewing text in a self-reflexive manner. Cognitive presence consists of four fundamental categories:

- The first category, triggering event, is where an educational problem is identified in order for students to make an inquiry about it (Garrison et al., 2001). Students will be identifying and conceptualising an issue or problem that needs to be investigated (Stenbom, Jansson, \& Hulkko, 2016).

- The second category is exploration. According to Garrison et al. (2000, p. 98), exploration involves searching "for information, knowledge and alternatives that might help to make sense of the situation or problem." Students will be exploring an issue under investigation in order to come up with a solution.

- The third category, integration, involves integrating gathered information and knowledge into one coherent idea or concept (Garrison et al., 2000). Integration involves "combining thoughts in order to make them operational" (Stenborn et al., 2016, p. 39). It requires students to connect ideas and make meaning from thoughts formed during exploration of the issue or problem (Fiock, 2020).

- The last category, resolution, involves "application of an idea or hypothesis" (Garrison et al., 2000, p. 99). Students will apply new knowledge and skills which they will have learnt (Fiock, 2020).

\section{Teaching presence}

Teaching presence is the most critical component of the $\mathrm{Col}$ as it binds social and cognitive presences to bring true online educational experiences. Garrison et al. $(2000$, p. 96$)$ reiterate the essence of teaching presence saying: "Appropriate cognitive and social presence, and ultimately, the establishment of a critical community of inquiry, is dependent upon the presence of a teacher." In other words, teaching presence is the foundation upon which social and cognitive presences rest. It (teaching presence) is essential as it balances cognitive and social presences in accordance with the intended educational outcomes. According to Rapanta et al. (2020), the teaching presence during the time of COVID-19 is indispensable as teachers design course materials, facilitate students' discussions and resolve any issue that may arise from students' learning. Simply put, teaching presence entails responsibilities of an instructor in online classes (Rourke \& Kanuka, 2009). Teaching presence consists of three main categories:

- Instructional management, which involves the designing and organisation of learning experiences in order to make it easy for students to navigate through a course (Fiock, 2020; Stenboen et al., 2016). According to Garrison et al. (2000, p. 101), "instructional management addresses structural concerns such as setting curriculum, designing methods and assessment, establishing time parameters and utilising the medium." Instructional management is also concerned with selection of collaborative learning activities and assessment strategies for students. Bates (2019) argues that designing appropriate course materials and selecting collaborative activities are very vital to the success of any online class.

- Building understanding involves productive and valid knowledge acquisition (Garrison et al., 2000). It involves facilitation of discourse where an instructor will be guiding and facilitating students' learning by guiding their discussions and ensuring that students engage with text in a focused and meaningful way (Garrison et al., 2001).

- Direct instruction involves the instructor directing students' learning in the right direction in accordance with the intended learning outcomes. According to Anderson (2004), direct instruction involves an instructor providing feedback to students' work, guiding their learning, correcting their misconceptions and giving relevant information.

The three components of Col along with their categories and indicators are summarised in Table 1. 
Table 1. Community of Inquiry Coding Template (Adapted from Garrison et al., 2000, p. 89)

\begin{tabular}{lll}
\hline Elements & Categories & Indicators (examples only) \\
\hline Social Presence & Emotional Expression & Emotions \\
& Open Communication & Risk-free expression \\
& Group Cohesion & Encouraging collaboration \\
\hline Cognitive Presence & Triggering Event & Sense of puzzlement \\
& Exploration & Information exchange \\
& Integration & Connecting ideas \\
& Resolution & Apply new ideas \\
\hline Teaching Presence & Instructional Management & Defining and initiating discussion topics \\
& Building Understanding & Sharing personal meaning \\
& Direct Instruction & Focusing discussion \\
\hline
\end{tabular}

Table 1 shows the Col's three elements (cognitive presence, social presence and teaching presence) along with their corresponding categories and indicators. Garrison et al. (2000) contend that the names of the categories and indicators were named so as to be somewhat self-explanatory.

The Col has been chosen as the most appropriate framework for this study as it has guided "many studies of e-learning in higher education" (Rourke \& Kanuka, 2009, p. 43). It is one of the widely used frameworks for building online communities in the 21st century and it is used to support ERT during the time of the global pandemic of COVID-19 (Fiock, 2020). It is important to note that although the Col has been chosen as an appropriate theoretical framework for this study, it has some limitations. A review conducted by Rourke and Kanuka (2009, p. 43) states that "deep and meaningful learning does not arise in Col." The Col framework is criticised for not having adequate empirical evidence which supports students' deep learning in online settings. Maddrell, Morrison, and Watson (2011) support the view that there is lack of evidence which shows that exposing students to the three components of Col leads to meaningful learning outcomes. Rourke and Kanuka (2009, p. 44) said, "conceptual frameworks of social presence, teaching presence and cognitive presence (and the corollary prescriptions for instructional designers) that are unconnected to empirical evidence of deep and meaningful learning are, on the face of it, groundless."

\section{Context of the study}

One of the main goals of the UAE's 2030 agenda is educational reform. Integration of technology in education is at the forefront of the planned reformation. It was stated in the UAE National Innovation Strategy (NIS) framework that there is a growing need for innovation in technology as it plays a primary role in shaping the future in order to ensure a better quality of life and education for individuals (UAE, 2015). The NIS aims to promote innovation and technology in the education sector through introducing creative teaching methods and techniques. This is in addition to designing and developing innovative curricula to equip students with the $21^{\text {st }}$ century skills and knowledge in the fields of science, technology, engineering, mathematics and the arts. In the UAE, a range of innovative technology initiatives were ushered in. These are the Smart Government and Smart City initiatives. Furthermore, the UAE launched a range of innovative projects in the education sector such as: Mohammed Bin Rashed Smart Learning Program (MBRSLP), the Emirates Foundation "Think Science" programme and the Abu Dhabi Center for Technical and Vocational Education and Training (ACTVET) launched "Emirates Skills" programme.

In response to the COVID-19 pandemic, all schools and universities in the UAE shifted to ERT in March 2020. Accordingly, educators adjusted their educational plans to suit the new teaching pedagogy. In preparation for ERT, university staff were encouraged to attend various professional development workshops, seminars and short courses to learn how to design online interactive activities. Two faculty instructors attended a short course which was offered by the Learning Resources Network (LERN), a globally accredited online instruction provider. The course was run over three months - June, July and August 2020 - and consisted of three parts:

- Part A: Fostering Online Discussion

- Part B: Designing Online Instruction 
- Part C: Advanced Teaching Online

There were assessments at the end of each component/part which were supposed to be passed with not less than $80 \%$ in order to proceed to the next part. After completing the three components/parts, there was a project which was submitted and a final examination written. Students who passed the course received certificates with a designation of certified online instructors "for achieving a standard of knowledge in the area of online instruction."

\section{METHODS}

This study was undertaken using an intrinsic case study that involves a qualitative approach within an interpretive paradigm. A qualitative approach was selected as it allowed participants to provide rich textual data (Creswell, 2012) about their reflections of establishing the components of a Col. The interpretive paradigm was selected as it is compatible with a qualitative approach. It enabled the two participants to freely express themselves in providing their reflections. According to Lapan, Quartaroli, and Riemer (2012), all qualitative research studies comprise of an interpretive perspective which allows participants to share rich textual data about a particular phenomenon. The study adopted a case study of two certified online instructors at a federal university in the UAE. A case study was chosen as it enabled selected participants to provide in-depth information about the phenomenon (Yin, 2018). In addition, the students' feedback surveys conducted by the university were analysed and interpreted to show the impact on students' learning.

\section{Participants}

Two certified online instructors were purposively selected to provide deep reflections on how they established social, cognitive and teacher presences during ERT. The certified online instructors (instructor 1 and instructor 2) were selected as they had completed a three month training course about designing and facilitating online teaching. It was therefore essential to tap into their views about establishing the Col during ERT. Instructor 1 is a female assistant professor with around four years' experience in higher education. Instructor 2 is a male assistant professor with around ten years' experience in higher education. Both instructors are involved in teaching educational studies courses.

\section{Instruments}

The study adopted a field note template where instructors wrote their reflections guided by the Col framework. The template included three categories, namely social, cognitive and teacher presences. In each category, there were sub-categories illustrated in Table 1. Regarding the tool's validity, the study adopted a Col framework (Garrison et al., 2000). The tool was tested by the study of Garrison et al. (2000), who postulate that students can have meaningful online learning experiences when they are exposed to the three categories of the Col.

The document analysis is used with the university students' survey of six courses in which three surveys were for the first instructor's students and three surveys were for the second instructor's students. The students' surveys, called SELE, are conducted every semester by the university to understand students' feedback about the course content and delivery. The analysis of the surveys was guided by the Col framework (Garrison et al., 2000). In order to check the quality of the surveys in respect to the study framework, the researchers selected a random sample to measure the interrated reliability. Two trained researchers coded six random surveys to calculate measures of the Cohen's K values. The surveys focused on students' evaluation of their experiences of online learning. The items selected form the surveys highlight how accessible the course content and materials were in light of the social, cognitive, and teaching presence. There were ten items selected in ( 3 items in social presence, 4 items in cognitive presence, and 3 items in teaching presence). In social presence, the focus was on creating a positive atmosphere, encouraging and respecting different ideas, and using educational technology effectively. In cognitive presence, the focus was on developing problem solving skills, stimulating new ways to think about the world, connecting ideas, and applying new skills. In teaching presence category, the focus was on sharing and discussing information about the topics, sharing 
personal meaning, and providing guidance on how to improve students' performances through discussion and constructive feedback. The Kappa value was measured to be 0.62 . According to Landis and Koch (1977), a Kappa value between 0.61 and 0.80 is in substantial agreement. Thus, the Kappa value of the document analysis is considered to be acceptable.

\section{Procedures}

Ethical issues were observed by first and foremost explaining the purpose of the study to the participants. Participation was voluntary, consent forms were signed and participants had the freedom to withdraw from the study at any point in time. Regarding the university surveys' document analysis, ethical approval was given by the university's research committee.

The first phase of the study was to collect data from the participants and code it according to the framework of the study. The second phase was the analysis of the students' surveys conducted by the university. The analysis of the survey included specific items that are related to the Col framework categories. The data was analysed using percentages of the students' responses to understand the impact of the social, cognitive and teaching presences in the online courses on students' experiences.

\section{RESULTS}

\section{Instructors' Reflection}

The results are presented in three different categories and sub-categories. The first category is the social presence that was interpreted in three different forms: open communication, emotional expression and group cohesion. The second category is the cognitive presence which is sub-categorised into: triggering events, exploration, integration and connecting ideas. Finally, the teaching presence is sub-categorised into instructional management, building understanding and direct instruction. The instructors used the Blackboard as the main learning management system and the Zoom meeting for the online classes. In addition, other platforms, apps and software were used to enhance the learning environments that are discussed.

\section{Social Presence}

\section{Open communication}

Instructor 1: The instructor facilitated the open communication with students through creating WhatsApp groups, posting reflective questions on Blackboard discussions, blogs, iCloud pages, numbers and keynotes. Students also completed different tasks in their weekly journals which required them to watch a video, analyse the scenarios and suggest recommendations and solutions to solve problems. The class meetings were done through the Zoom meeting app where they met with the instructor, collaborated with their colleagues through the breakout rooms and shared their opinions through the poll. The breakout rooms were created with a precise time decided for students where each group (2-5 students) met to discuss, share ideas and complete their tasks. Once the breakout room time was over, students entered the main meeting automatically to meet with the instructor as a whole class group.

Instructor 2: The instructor created a conducive online environment which allowed students to feel free to contribute to different online platforms which were used. Students communicated openly throughout the course without fear of being judged, labelled or intimidated. They communicated through different platforms which include Google slides, Google forms, Padlet and a WhatsApp group.

Student participation was made compulsory. They were encouraged to actively participate during Zoom classes and to complete tasks which were posted on Blackboard's discussion forums. Students would not see other students' comments unless they posted theirs. They critiqued each other's work and discussed comments which were posted by others which they were not clear about. 


\section{Emotional expression}

Instructor 1: The instructor facilitated the use of formal and informal communication with students. In the introduction forum, students responded in informal answers to introduce themselves, share their interests, needs, learning styles, fun facts and find commonalities between themselves and their peers. The instructor provided students with links to some personality tests and learning styles where students understood their personality types and their learning needs. Students were grouped according to their personality types and shared information about themselves. The introduction activity was set as an icebreaker for students to let them know each other and to communicate. The rules about the respective way of communication were defined to students at the beginning of the semester.

Other informal communications were done with student-student and student-instructor through informal messages on WhatsApp, informal emails and meetings with the instructor during office hours. The office hours were set virtually on specific days and at specific times every week. Students were free to join the meetings through a Blackboard platform link provided to them as well as by meeting with the instructor on a one-to-one basis. They shared concerns, fears and opinions about different aspects in the course and about assessments.

Instructor 2: The instructor discouraged students from making personal and negative comments on other students' work. Instead, they were encouraged to be very critical, while remaining objective throughout. Students had the freedom to express their innermost feelings related to the educational experience and some constructive comments were shared by students on Blackboard's discussion forum. At first, some students felt unhappy about the comments, but they acknowledged that it was a good learning experience as they learnt a lot from other students' insights. Students freely expressed themselves in all discussions they had on Blackboard, Nearpod and Padlet.

\section{Group cohesion}

Instructor 1: Students worked in groups through the breakout rooms created during the online Zoom meetings to complete their classwork activities. Students worked together when criticising an integrated lesson plan. They used iCloud apps (sheets and keynotes) to analyse the lesson, write suggestions for improvements and use evidence to support their arguments. Students worked together to plan and microteach learning centres, projects and themes. They used iCloud apps (sheets) to do the planning and for organising the process of the projects and themes. For micro-teaching, students used different apps such as iCloud (keynotes and pages) to create interactive stories and presentations. They also used different apps to co-create interactive videos such as Canva, Record it Pro and iMovie. Few students used augmented reality apps to create dinosaurs where they could do play-based learning with early years students.

In other courses, students had the opportunity to collaborate while doing a video observation. They watched the video and discussed the items observed in breakout rooms. They worked in groups using Padlet to answer reflective questions about the observations. Students also compared two types of observations (in class and online learning). They used Google docs to analyse and write their comments on the observation items that could not be used in online learning. They suggested improvements in the items to observe online classes.

Instructor 2: Students worked collaboratively when developing an intervention programme for children. They worked in small groups and sometimes in pairs. They collaborated when brainstorming the topic, during the time of writing the intervention and after the intervention. Students collaborated on the Teacher Candidate Impact on Students' Learning (TCISL) through different platforms which include Google docs, Google slides, Padlet and Nearpod. There was student collaboration throughout the course. They worked together to provide reflective journals which were submitted on Blackboard. Students collaborated when working on each of the four assessments in the course. 


\section{Cognitive Presence}

\section{Triggering event}

Instructor 1: As part of classwork, students were given some real-life scenarios that needed to be analysed and suggested solutions for the problems identified. In addition, pre-service teachers were given some video observations as part of their coursework to observe, analyse and recommend ideas for improving learning environments. Students held a debate about the difference between in-class observation and online observation. They distributed the roles among each other and argued their points of view respectfully.

Students were asked to design an online learning environment for early years and suggest ways of communication with parents. They worked on providing a home learning pack for early years students that included some virtual meetings with students and parents. The learning packs consisted of links to interactive stories, activities that require students to meet virtually with their teachers and interact through the online dramatic play. As some of the pre-service teachers are parents, they applied some of the themes with their children and shared this. Other activities included simple experiments called "My Creative Sandwich" where pre-service teachers did the activity with their children by using different cutter shapes and doing faces and animals from the sandwiches' ingredients. They recorded their children and shared the videos during class time. In addition, students were given several journal entries throughout the semester that required them to reflect on different tasks that they completed such as: learning centres, themes, projects, micro-teaching, lesson plans critique and analysing real-life scenarios. Students worked on the journal entries individually using the journal feature on the Blackboard.

Instructor 2: Internship students were presented with an educational problem: children with dyslexia who had a challenge with letter reversal without knowing the direction of the letters. The students were asked to conceptualise and brainstorm the problem, work collaboratively and develop a hypothetical intervention programme to assist dyslexic children.

Students were asked to search for information on constructive alignment. They were given various lesson plans to critique. They were also shown videos about components of a lesson plan and they were asked to design their lesson plans which demonstrate understanding of constructive alignment.

\section{Exploration}

Instructor 1: Instructors worked on providing students with two to three open-ended questions every week to guide the preparation and exploration of the topic that will be discussed. Thereafter, students discussed these questions in the beginning of the class time. Tasks about defining learning theories and how to apply them were distributed to students. They searched for the information, discussed the ideas, provided some pictures and suggested ways of application using an iCloud app (numbers).

Some authentic tasks were used that allow pre-service teachers to search for information and alternatives on planning lessons for online classes. Students searched for successful stories about teaching early years online using interactive stories, recorded videos, presentations and parents' involvement. In addition, students explored ways to teach children with special educational needs such as visual impairment, dyslexia and other learning difficulties.

Instructor 2: Students examined the nature of the problem and realised that dyslexic children had difficulty writing and recognising letters $b, d, p$ and $q$. Students searched for information on the internet about the nature of the problem experienced by children and how to help them overcome it. They consulted their mentor teachers about helping the dyslexic children who were identified. Students consulted university supervisors after searching for possible ways to overcome children's learning difficulty.

Students worked in groups synchronously and asynchronously. Synchronously, they met in breakout rooms on Zoom. Asynchronously, they worked on Google docs. They brainstormed the work together using Padlet. 


\section{Integration}

Instructor 1: Pre-service teachers used the content knowledge and skills acquired to plan for theme-based learning, project-based learning and learning centres. They used the inquiry model - 5Es (Engage, Explore, Explain, Elaborate and Evaluate) - and engineering design processes they learned and the math, science and literacy contents to create and teach mini lessons. These tasks were done collaboratively in groups comprising four to five students. For micro-teaching, pre-service teachers had the choice of recording a video, presentation, or teaching live in an online Zoom session. Students received feedback about their work focusing on suggestions for improvement.

Instructor 2: Students integrated and synthesised information they gathered from internet searches, consultation with mentor teachers and university supervisors. Students connected the ideas they gathered and developed coherent intervention programmes to assist children with reading and writing letters, $b, p, q$ and $\mathrm{d}$. Intervention programmes developed show different steps which students undertook to educate children about reading and writing those letters.

Students compiled information they discussed to make coherent lesson plans. The lesson plans were presented on the institution's lesson plan template.

\section{Resolution}

Instructor 1: Pre-service teachers worked together in suggesting areas for improvement while observing different learning environments. They also suggested some changes in the observation tools used to observe online learning classes that were different from the tool they used to observe in-class learning environments.

Students also received feedback on their journal entries and had the opportunity to improve their work and edit it. They also analysed real-life scenarios and suggested areas for improvement.

Instructor 2: Students developed a poster and narrative report on the entire intervention programme. Each student presented their intervention programme to the university supervisor and received some feedback which they used to improve their work. Some students applied their intervention programmes to children they were teaching. Students critiqued the programme and made some improvements based on weaknesses they would have identified.

Students applied their lesson plans in a micro-teaching scenario where they selected any child (siblings in early childhood) and conducted a lesson. The lessons were guided by what was stated in the lesson plans. Students recorded their lessons and submitted the recording and lesson plan for marking.

\section{Teaching Presence}

\section{Instructional management}

Instructor 1: The courses were designed using Blackboard to include the basic components of instructional design: syllabus, overview of the course, introduction, weekly instructional materials, assessment materials, discussion forums and announcements. Each week included an introduction page about the week, learning outcomes, reading materials, video links, website links and activities. The discussion forums were organised to include rules for communication and different forums: introduction of students and instructor, frequently asked questions (FAQs), sharing opinions and weekly reflection. Students were tasked with responding to the introduction, weekly reflection, asking any question in the FAQs and responding to two of their colleagues' postings.

Instructor 2: Students would not have participated in ERT if it was not for the instructor who selected and organised the learning experiences compatible with online learning. The instructor had to design course materials, students' learning activities and assessments which were suitable for remote learning. The instructor would devise collaborative activities for students to do online so that they felt as if they were interacting in face-to-face classes with their peers. 
The instructor had to change the whole course from face-to-face to online format. The course learning outcomes, teaching and learning materials and assessment strategies were changed to suit the remote learning modalities.

\section{Building understanding}

Instructor 1: The instructor used different methods to build students' understanding while having synchronous and asynchronous classes through:

- Using "Record it Pro" to explain the assignments and difficult topics while surfing between the websites, pages and presentations.

- Using "Zoom Recording" to keep records available for their references in case needed again.

- Facilitating the discussion through asking probing follow-up questions that enhance the discussion on the topic especially when the interactions were getting slower.

- Announcements about the important dates and submissions were used to keep students reminded about their work

- The weekly emails were used to summarise important points of the current week to share and emphasise the important events and topics of the upcoming week.

Instructor 2: The instructor guided students' learning throughout the course. Even when students were doing self-regulated learning, the instructor ensured that they were going in the right direction. The instructor would then allow all students to post their threads on Blackboard and he then encouraged each student to provide at least three comments regarding other students' work. The instructor would read all the submitted comments to ensure that every student's concern was addressed. In instances where students would not comment on each other's work, the instructor formulated a question for all students to comment.

The instructor oversaw all the work which students were submitting. He encouraged inactive students to take part and provide comments on students' discussions on Google docs, Padlet and in Zoom breakout rooms. The instructor practiced continual engagement which encouraged students to be involved in remote learning.

\section{Direct instruction}

Instructor 1: To further develop pre-service teachers' understanding and improve their learning, they were encouraged to send their work to the instructor a week before the submission due date. The instructor provided the students with written constructive feedback that helped them to improve their work.

Other feedback was provided during the scheduled office hours announced by the instructor for one-to-one meetings. Six weekly office hours were designated for meeting with students online throughout the semester. In addition, some students met the instructor during break time while others would contact the instructor for private appointments. The reason for meeting with students online was to give them feedback and to address any individual concerns that they might have had.

Instructor 2: The instructor provided feedback to students' learning. Each time a student posted something, the instructor would allow other students to comment first. He would then provide overall feedback which addressed all students' comments.

Some students who missed Zoom classes were not clear about the instructions for tasks posted on Blackboard. The instructor would assist them by creating an audio or video using Screencast-o-matic to explain all the instructions about the task to be performed.

\section{Students' feedback}

Figures $\mathbf{2}$ and $\mathbf{3}$ show the students' agreements about the items related to social presence (emotional expression, open communication and group cohesion), cognitive presence (triggering events, exploration, integration and resolution) and teaching presence (instructional management, building understanding and 


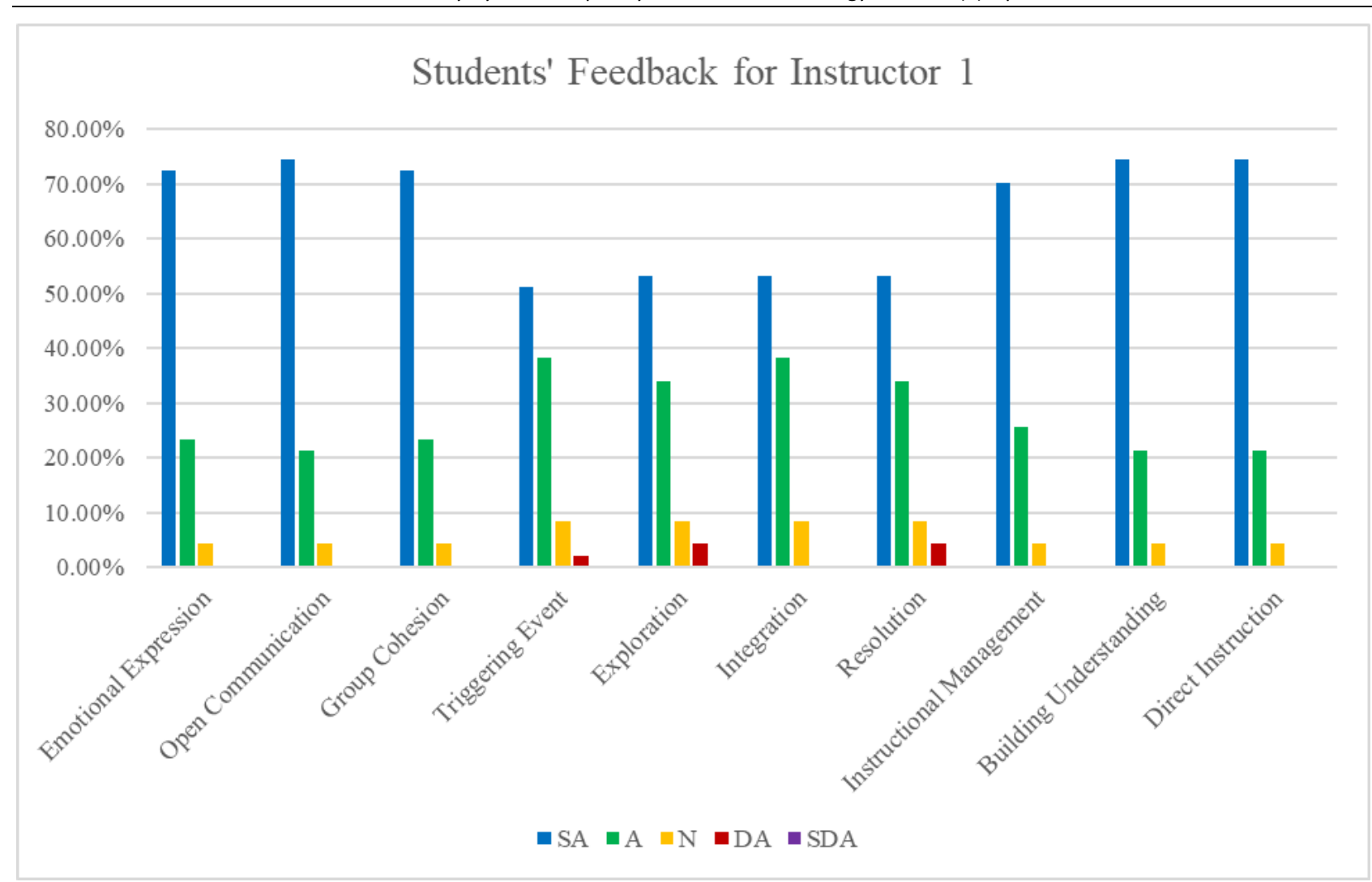

Figure 2. The First Instructor's Students' Feedback on the Online Courses

direct instruction). The responses were categorised according to the level of students' agreement from Strongly Agree (SA), Agree (A), Neutral (N), Disagree (DA) and Strongly Disagree (SDA).

In Figure 2, the responses by the first instructor's students showed high agreement in all items of the Col categories. However, few disagreements were found in the following categories of the cognitive presence: triggering events (2.13\%), exploration (4.26\%) and resolution (4.26\%).

In Figure 3, the responses by the second instructor's students show high agreement in all categories. Few students (5.56\%) showed disagreement in two items of the cognitive presence related to triggering events and resolution.

The establishment of the three elements of the Col was not only successful, but also effective. This was confirmed by pre-service teachers whose feedback was overwhelming. The students reported that they learnt a lot from online learning which they were pessimistic about in the beginning. 


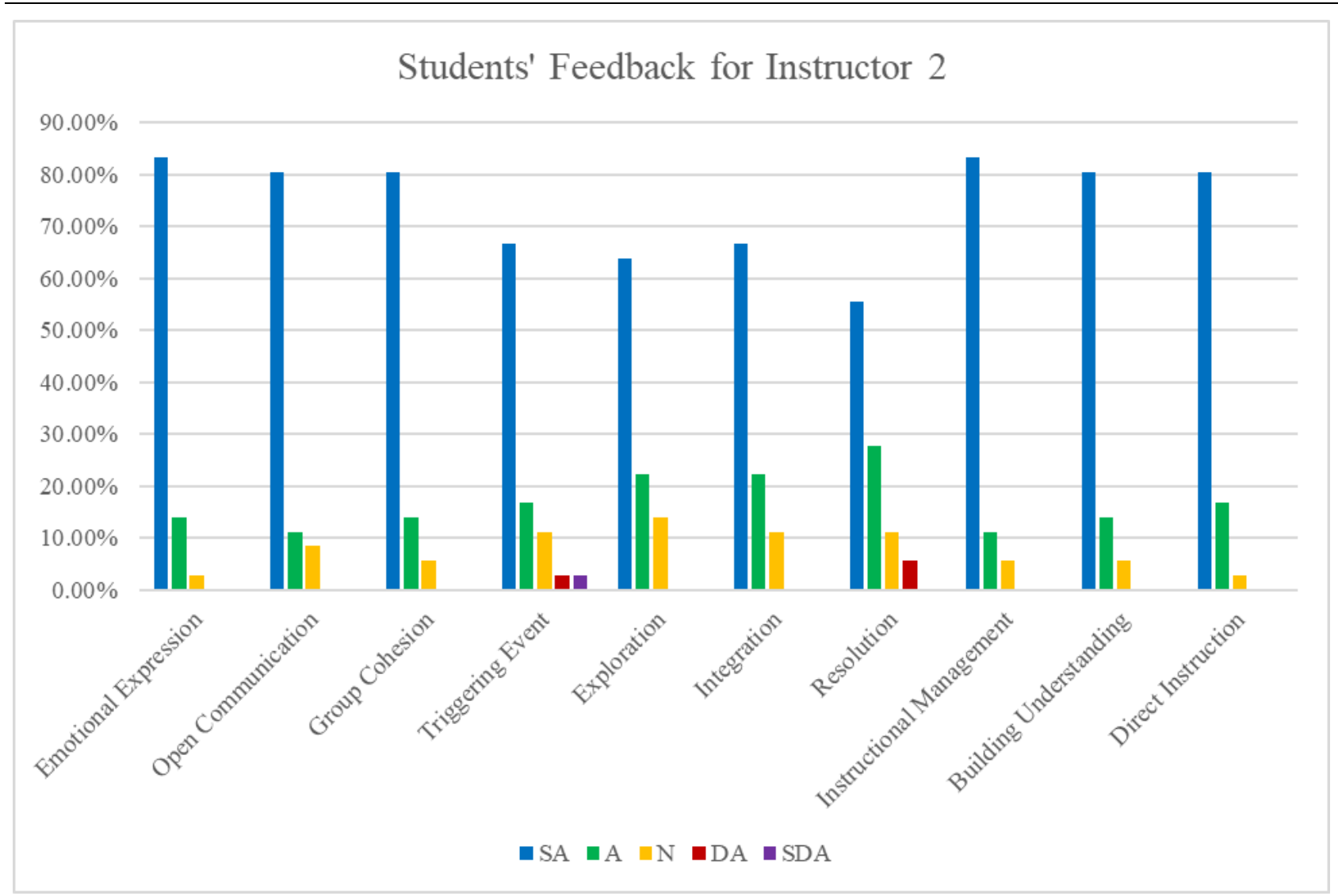

Figure 3. The Second Instructor's Students' Feedback on the Online Courses

\section{DISCUSSION}

In this study, three components of the Col were established through continual engagement, self-regulated learning and student interaction. This concurs with Waghid (2016) who argues from a South African context that social, cognitive and teacher presences were established by pre-service educators by using film and online group blogs. Draves (2013) observed that when students interact with their fellows online, they use their critical thinking skills to solve problems and by having a teacher guiding their learning, online learning goals are easily attained. Garrison et al. (2000) underscore this point arguing that every online class needs to have activities which project students as real people in an online community. This relates to the social presence which was established in this study by using different technologies to develop various engaging activities for students to do in groups. Social presence can be established in many ways if it require students to interact with the instructor and other students. Watson, Watson, Richardson and Loizzo (2016) established the social presence in a Massive Open Online Course (MOOC) by simply using students' names, acknowledging their contributions, using salutation and interacting with them extensively. Engagement is at the heart of ERT. Any form of online learning needs to be strengthened in a way that allows all students to actively participate in the course (Whittle et al., 2020).

In some instances, student engagement may be a challenge in ERT due to its nature of occurring suddenly and giving instructors insufficient time to plan. The suddenness of ERT in response to a global pandemic such as COVID-19 made it difficult for both instructors and students to adjust and participate in some engaging virtual activities (Crawford et al., 2020). In this study, students' engagement was a challenge to participants until they capacitated themselves by taking professional development courses aligned to designing online interactive activities for students.

Cognitive presence was evident throughout this study as students exercised self-regulated learning and had opportunities to solve problems independently while using their critical thinking skills to develop creative and innovative designs. This is consistent with Huho's (2020) study in Kenya where students applied their 
cognitive skills to develop ventilators and COVID-19 test kits. This was a sign of innovation and creativity which was attributed to the cognitive presence during ERT. Students in Kenyan universities were afforded opportunities to learn independently, become creative and employ inquiry-based learning strategies (Nyamboga \& Ali, 2020).

Findings of this study concur with the view by Garrison et al. (2000) that teaching presence is what holds students' collective online learning experiences. If social presence is essential in ERT, so is teacher presence, as there is a need for an instructor to meticulously select, plan, organise and implement students' learning experiences in any given course. Teacher presence was evident in this study as instructors designed a curriculum for their courses, provided direct instruction and guided students' learning in all the activities that they were doing. Similarly, Watson et al. (2016) established teacher presence in a MOOC by clarifying issues, giving examples, providing resources (direct instruction) and summarising issues as a way of facilitating discourse. Thus, it is important for instructors to practice continual engagement (Draves, 2013) and provide feedback to students throughout the course (Anderson, 2004). If this does not happen, students may stop participating in online activities as they might not see value unless the instructor shows he/she is present by commenting on their work. Discussion forums work effectively when students see that their instructor is following their postings. This is supported by an instructor who said "the discussion platforms really worked. Any hour of the day I would go in and I would see someone typing in something - two minutes ago, one minute ago" (Watson et al., 2016, p. 64).

\section{LIMITATIONS AND RECOMMENDATIONS}

The results of this study cannot be generalised as the sample consisted of only two certified online instructors and analysis of six SELEs. The researchers recommended that further studies focusing on similar constructs be explored, but using different institutions and paradigmatic positions and approaches. A study can also be conducted using a mixed approach while allowing more participants to cater for generalisation.

\section{CONCLUSION}

The purpose of this case study was to examine ways in which certified online instructors established social, cognitive and teacher presences during ERT at a university in the UAE. Results showed that participants established the three critical components of the Col in multiple ways thereby disagreeing with Rouke and Kanuka's (2009) assertion that one of the limitations of a Col framework is that it does not allow meaningful learning to occur. The reflections provided by the two certified online instructors show a high level of student engagement (which is indicative of social presence), opportunity for pre-service teachers to practice selfdirected learning and apply critical thinking skills (indicative of cognitive presence) and continual engagement (indicative of the teacher presence). Although all three presences (social, cognitive and teacher) are inseparable and equally important, social presence is core as it enables students to have a practical contact of human aspects within an online community. The study concludes that the establishment of the three components of a Col impacts remote learning in a positive way as it enhances students' learning experiences and allows instructors to cater for the diverse learning needs of all students in an online community.

Author contributions: All authors were involved in concept, design, collection of data, interpretation, writing, and critically revising the article. All authors approve final version of the article.

Funding: The authors received no financial support for the research and/or authorship of this article.

Declaration of interest: Authors declare no competing interest.

Data availability: Data generated or analysed during this study are available from the authors on request.

\section{REFERENCES}

Affouneh, S., Salha, S., \& Khlaif, Z. N. (2020). Designing quality e-learning environments for emergency remote teaching in coronavirus crisis. Interdisciplinary Journal of Virtual Learning in Medical Sciences, 11(2), 135-137. https://doi.org/10.30476/ijvlms.2020.86120.1033 
Anderson, T. (2004). Teaching in an online learning context. In T. Anderson \& F. Elloumi (Eds.), Theory and practice of online learning (pp. 273-294, $2^{\text {nd }}$ ed.). Athabasca University Press.

Anderson, T., \& Dron, J. (2011). Three generations of distance education pedagogy. International Review of Research in Open and Distributed Learning, 12(3), 80-97. https://doi.org/10.19173/irrodl.v12i3.890

Bates, A. W. (2019). Teaching in a digital age ( $2^{\text {nd }}$ ed.). Tony Bates Associates Ltd. https://pressbooks.bccampus.ca/teachinginadigitalagev2/

Bozkurt, A., \& Sharma, R. C. (2020). Emergency remote teaching in a time of global crisis due to Coronavirus pandemic. Asian Journal of Distance Education, 15(1), 1-4. https://doi.org/10.5281/zenodo.3778083

Bozkurt, A., Jung, I., Xiao, j., Vladimirschi, V., et al. (2020). A global outlook to the interruption of education due to COVID-19 Pandemic: Navigating in a time of uncertainty and crisis. Asian Journal of Distance Education, 15(1), 1-126. https://asianjde.org/ojs/index.php/AsianJDE/article/view/462

Crawford, J., Butler-Henderson, K., Rudolph, J., Malkawi, B., Glowatz, M., Burton, R., Magni, P. A., \& Lam, S. (2020). COVID-19: 20 countries' higher education intra-period digital pedagogy responses. Journal of Applied Learning \& Teaching, 13(1), 9-28.

Creswell, J. W. (2012). Educational research: Planning, conducting and evaluating quantitative and qualitative research. Pearson.

Draves, W. A. (2013). Advanced teaching online. LERN Books.

Fiock, H. S. (2020). Designing a community of inquiry in online courses. International Review of Research in Open and Distributed Learning, 21(1), 134-152. https://doi.org/10.19173/irrodl.v20i5.3985

Garrison, D. R. (2007). Online community of inquiry review: Social, cognitive, and teaching presence issues. Journal of Asynchronous Learning Networks, 11(1), 61-72. https://doi.org/10.24059/olj.v11i1.1737

Garrison, D. R. (2015). Thinking collaboratively: learning in a community of inquiry. Routledge. https://doi.org/10.4324/9781315740751

Garrison, D. R., Anderson, T., \& Archer, W. (2000). Critical inquiry in a text-based environment: Computer conferencing in higher education. The Internet and Higher Education, 2(2-3), 87-105. https://doi.org/10.1016/S1096-7516(00)00016-6

Garrison, D. R., Anderson, T., \& Archer, W. (2001). Critical thinking, cognitive presence, and computer conferencing in distance education. American Journal of distance education, 15(1), 7-23. https://doi.org/10.1080/08923640109527071

Gutiérrez-Santiuste, E., Rodríguez-Sabiote, C., \& Gallego-Arrufat, M. (2015). Cognitive presence through social and teaching presence in communities of inquiry: A correlational-predictive study. Australasian Journal of Educational Technology, 31(3), 349-362. https://doi.org/10.14742/ajet.1666

Huho, J. M. (2020). The two sides of Covid-19 in Kenya: getting a closer look. International Journal of Scientific and Research Publications, 10(8), 478-484. https://doi.org/10.29322/IJSRP.10.08.2020.p10459

Karkar, A. J., Fatlawi, H. K., \& Al-Jobouri, A. A. (2020). Highlighting e-learning adoption challenges using data analysis techniques: University of Kufa as a case study. Electronic Journal of e-Learning, 18(2), 136-149. https://doi.org/10.34190/EJEL.20.18.2.003

Kibuku, R. N., Ochieng, D. O., \& Wausi, A. N. (2020). e-learning challenges faced by universities in Kenya: A literature review. The Electronic Journal of e-Learning, 18(2), 150-161. https://doi.org/10.34190/EJEL.20.18.2.004

Kreijns, K., Van Aker, F., Vermeulen, M., \& Van Buuren, H. (2014). Community of inquiry: Social presence revisited. E-Learning and Digital Media, 11(1), 5-18. https://doi.org/10.2304/elea.2014.11.1.5

Landis, J. R., \& Koch, G. G. (1977). The measurement of observer agreement for categorical data. Biometrics, 33(1), 159-174. https://doi.org/10.2307/2529310 
Lapan, D. S., Quartaroli, T. M., \& Riemer, J. F. (2012). Introduction to Qualitative Research. In S. D. Lapan, T. M. Quartaroli, \& J. Riemer (Eds.), Qualitative research: An introduction to methods and designs (pp. 318). Josey-Bass.

Maddrell, J. A., Morrison, G. R., \& Watson, G. S. (2011, November). Community of inquiry framework and learner achievement [Paper presentation]. Annual Meeting of the Association of Educational Communication \& Technology, Jacksonville, FL. http://www.jennifermaddrell.com/wpcontent/uploads/2011/11/MADDRELL-MORRISON-WATSON-AECT-Featured-Research-Paper-FINAL20111110.pdf

Ngwacho, A. G. (2020). COVID-19 Pandemic impact on Kenyan education sector: learner challenges and mitigations. Journal of Research Innovation and Implication in Education, 4(2),128-139.

Nyamboga, T. O., \& Ali, H. A. (2020). Adoption of digital literacy strategy on academic progress of private university education in Kenya: A survey of Umma University, Garissa Campus. Asian Journal of Economics, Business and Accounting, 19(2), 24-39. https://doi.org/10.9734/ajeba/2020/v19i230300

Ontong, K., \& Waghid, Z. (2020). Towards cultivating a critical pedagogy of place: a response to teaching practices in higher education amidst COVID-19. In L. Ramrathan, N. Ndimande-Hlongwa, N. Mkhize, \& J.A. Smit (Eds.), Re-thinking the humanities curriculum in the time of COVID-19 (pp. 56-73, Alternation African Scholarship Book Series, Volume \#01). CSSALL Publishers.

Rapanta, C., Botturi, L., Goodyear, P., Guàrdia, L., \& Koole, M. (2020). Online university teaching during and after the Covid-19 crisis: Refocusing teacher presence and learning activity. Postdigital Science and Education, 2(2020), 923-945. https://doi.org/10.1007/s42438-020-00155-y

Rourke, L., \& Kanuka, H. (2009). Learning in communities of inquiry: A review of the literature. Journal of Distance Education, 23(1), 19-48.

Stenbom, S., Jansson, M., \& Hulkko, A. (2016). Revising the community of inquiry framework for the analysis of one-to-one online learning relationships. International Review of Research in Open and Distributed Learning, 17(3), 36-53. https://doi.org/10.19173/irrodl.v17i3.2068

UAE. (2015). UAE national innovation strategy. UAE Ministry of Cabinet Affairs.

Waghid, Z. (2016). Using film and online group blogs to cultivate a community of inquiry: A case at a university of technology in South Africa. Progressio: South African Journal for Open and Distance Learning, 38(2), 106-131. https://doi.org/10.25159/0256-8853/2103

Watson, S. L., Watson, W. R., Richardson, J., \& Loizzo, J. (2016). Instructor's use of social presence, teaching presence, and attitudinal dissonance: A case study of an attitudinal change MOOC. International Review of Research in Open and Distributed Learning, 17(3), 54-74. https://doi.org/10.19173/irrodl.v17i3.2379

Whittle, C., Tiwari, S., Yan, S., \& Williams, J. (2020). Emergency remote teaching environment: A conceptual framework for responsive online teaching in crises. Information and Learning Sciences, 121(5/6), 311319. https://doi.org/10.1108/ILS-04-2020-0099

Yin, R. K. (2018). Case study research and applications: Design and methods. Sage Publications.

Zhang, W. N., Wang, Y. X., Yang, L. L., \& Wang, C. Y. (2020). Suspending classes without stopping learning: China's education emergency management policy in the COVID-19 outbreak. Journal of Risk and Financial Management, 13(55), 2-6. https://doi.org/10.3390/jrfm13030055

Correspondence: Lawrence Meda, Zayed University, Dubai, United Arab Emirates.

E-mail: medalawrence@gmail.com 